\title{
La huelga de 1966 en el Puerto de Buenos Aires. ¿Caso excepcional de resistencia o preludio de la radicalización?
}

\section{The 1966 port strike in Buenos Aires. An exceptional case of resistance or a prelude for growing radicalization?}

\author{
Martín Mangiantini \\ Instituto de Historia Argentina y Americana Dr. Emilio Ravignani \\ Universidad de Buenos Aires \\ Consejo Nacional de Investigaciones Científicas y Técnicas \\ martinmangiantini@gmail.com
}

(Argentina)

\section{Resumen}

El artículo aborda la huelga acaecida en el puerto de Buenos Aires entre los meses de octubre y diciembre de 1966 en los inicios de la autodenominada "Revolución Argentina" convirtiéndose en el punto de partida de una política de racionalización empresarial por parte del “Onganiato". Si bien los resultados del conflicto son factibles de ser caracterizados como adversos para sus protagonistas se sostiene que, en perspectiva, su derrotero anticipó un considerable abanico de elementos que se identificaron con claridad tras las jornadas de mayo de 1969 en el marco del proceso de radicalización político-ideológica identificable con el conjunto de fenómenos externalizados tras el "Cordobazo".

Palabras Clave: portuarios, racionalización, “Onganiato”. 


\begin{abstract}
:
The article addresses the strike at the port of Buenos Aires between the months of October and December 1966 during the beginning of the dictatorship of Onganía. This conflict became the beginning of a business rationalization defended by the government. The result of the conflict was negative for workers. However, its characteristics anticipated some elements which can be identified more certainly after May of 1969, during the political and ideological radicalization process that was lived with the denominated Cordobazo.
\end{abstract}

Keywords: port workers, rationalization, Onganía’s dictatorship.

$$
\propto \tilde{e} \propto
$$

\section{Introducción}

El presente artículo aborda la huelga acaecida en el puerto de Buenos Aires entre los meses de octubre y diciembre de 1966 en los inicios de la autodenominada "Revolución Argentina", transformada en el punto de partida de una política de racionalización empresarial por parte del "Onganiato".

Si bien los resultados del conflicto son factibles de ser caracterizados como adversos para sus protagonistas se sostiene que, en perspectiva, su derrotero anticipó un considerable abanico de elementos que se identificaron con claridad tras las jornadas de mayo de 1969 en el marco del proceso de radicalización político-ideológica asimilado al conjunto de fenómenos externalizados tras el Cordobazo. En ese sentido, a partir de un estudio de caso, la propuesta recae en reflexionar en torno a determinadas características que, vislumbradas con claridad tras el estallido cordobés, se hallaban presentes en el proceso de resistencia inicial a las lógicas racionalizadoras que trajo consigo el golpe de Estado de $1966 .{ }^{1}$

1. Una versión anterior de este trabajo fue debatida en el 54
E1 conflicto portuario tuvo, historiográficamente, un abordaje fragmentario. Schneider (2005) se ocupó de él de modo sintético a través de una valiosa descripción que lo encuadró dentro de las primeras resistencias obreras al gobierno de Onganía. También, menciones pasajeras dentro de una estructura narrativa más general sobre la conflictividad del período y el rol de las dirigencias sindicales se reflejan en las obras de Anzorena (1988) y James (1990). Por su parte, en los trabajos de Ernesto González (1999) y Martín Mangiantini (2018) se menciona el papel desarrollado por una organización, el Partido Revolucionario de los Trabajadores (en adelante, PRT), en el derrotero de esta huelga. Más específicamente, Agustín Nieto (2011) y Ana Belén Zapata (2017) dieron cuenta de la conflictividad en el rubro portuario en este momento pero no en el ámbito porteño-bonaerense sino, respectivamente, en Mar del Plata y Bahía Blanca. El trabajo de Nieto (2011) se preocupó por su abordaje priorizando la indagación del papel

marco de las IX Jornadas de Historia Reciente. Agradezco los comentarios y aportes de Pablo Ghigliani, Alejandro Schneider y Mónica Gordillo, como así también las sugerencias realizadas por los evaluadores de Avances del Cesor. 
desempeñado desde los años cuarenta por los organismos de base de los portuarios (como las comisiones de fábrica o los cuerpos de delegados) en la concreción de una multiplicidad de conflictos particulares que, para el autor, abonaron a moldear un proceso de democratización que encontró a la clase obrera como protagonista. Por su parte, Zapata destaca, por un lado, que la huelga portuaria de 1966, independientemente de su resultado, redundó en un punto de partida para futuros reclamos sobre condiciones de trabajo y organización del trabajo portuario bahiense. En otro orden, para la autora, este caso reviste importancia porque, según su análisis, la experiencia regional tuvo características aún más álgidas y prolongadas que el propio devenir nacional del conflicto centralizado en Buenos Aires.

Los trabajos más acabados sobre el tema fueron los elaborados conjuntamente por Patricia Berrotarán y José Villarroel (1994) y la producción de Valeria Snitcofsky (2011). El primero de ellos realiza un recorrido por la situación de los estibadores desde el golpe de Estado de 1955, haciendo hincapié en las formas de trabajo y organización gremial. La ofensiva y el proceso de racionalización de 1966 es analizada como el cierre de un ciclo en el que se intentaron, hasta entonces sin éxito, distintas iniciativas de racionalización de la labor portuaria. Snitcofsky (2011), por su parte, tiene la virtud de indagar el conflicto portuario desde un aspecto original, la organización territorial gestada a través de las villas durante el transcurso de la huelga. No obstante, en esta explicación omite un elemento fundamental para entender el origen y dinámica de los nuevos organismos: la participación de diversas organizaciones políticas que colaboraron en su concreción y desarrollo.
Desde otro ángulo, es factible reflexionar en torno a este conflicto no solo como parte de un plan de racionalización particular del régimen militar argentino sino también como un ejemplo de un proceso de transformación de la actividad portuaria que, en los años sesenta y setenta, experimentaron diversos países latinoamericanos (Sepúlveda, 1987; Agostini y Saavedra, 2003 y Doerr, 2011) dando cuenta de una deuda historiográfica que se proponga un abordaje en perspectiva transnacional y comparativa.

En este trabajo se realizará un entrecruzamiento de fuentes a los efectos de dar cuenta de una mirada política del conflicto centralizada en los insumos partidarios y sindicales. El abordaje se realizó a partir de la utilización de diversos recursos. Por un lado, publicaciones periodísticas comerciales de tirada diaria como La Nación, Clarín y Crónica o semanal como Primera Plana (En adelante, PP). Por otro, la utilización de las publicaciones editadas por diversas organizaciones pertenecientes al campo de las izquierdas o del peronismo combativo que intervinieron de diverso modo en el conflicto tales como La Verdad (órgano del PRT), Política Obrera (perteneciente al partido homónimo), No transar (de Vanguardia Comunista), Nuestra Palabra (del Partido Comunista), Lealtad (de Acción Revolucionaria Peronista) y Cristianismo y Revolución. En los casos del PRT y de la Acción Revolucionaria Peronista se utilizó también documentación de circulación interna de las respectivas organizaciones. Por su parte, se indagó aquel material elaborado en el seno de los organismos de carácter territorial surgidos durante el conflicto como los "boletines de huelga", desarrollados por la Coordinadora de comités de resistencia de las villas. Por último, se abordó el propio balance del conflicto 
elaborado por la dirigencia sindical que orientó su derrotero (Tolosa, 1969).

\section{El conflicto portuario: el desarrollo de sus problemáticas}

Entre 1966 y 1967, se experimentó una ofensiva gubernamental contra la clase trabajadora a través de políticas como la racionalización empresarial, el alza de la recaudación impositiva, el aumento de las tarifas de los servicios y la reducción del número de empleados públicos y empresas estatales. El incremento de la productividad del trabajo, el congelamiento salarial, la devaluación de la moneda y la suspensión de los convenios colectivos fueron las expresiones más firmes del avance gubernamental contra conquistas antes obtenidas. El proyecto golpista conjugó una acelerada modernización económica con una fuerte exclusión social y política, modelo que trajo aparejado la pérdida de numerosas fuentes de trabajo y la imposición de adversas condiciones laborales a partir de criterios de racionalidad (O' Donnell,1982 y Peralta Ramos, 2007).

En este marco, y a modo de ensayo, tres rubros experimentaron inicialmente la ofensiva estatal de ajuste y racionalización: el portuario, el ferroviario y los trabajadores de los ingenios azucareros. En particular, en el caso portuario, el proceso de racionalización consistió en la aplicación de una serie de reformas tendientes a modificar lo que el Estado visualizaba como una forma de remediar la improductividad y el gasto público. De hecho, en 1961, el gremio portuario logró evitar el "Plan Perren", anterior intento de racionalización que sirvió como modelo para las reformas a aplicar (Berrotarán y Villarroel, 1994).
En los albores de la reforma, la mano de obra empleada para las tareas portuarias era fluctuante. En Buenos Aires, entre 12 y 15 mil hombres se turnaban y realizaban labores que precisaban de entre tres a cinco mil personas diarias en un régimen de contratación semilibre que redundaba en un tipo de trabajo que no superaba los 10 a 15 días promedio de ocupación mensual dado el tipo de tareas de riesgo e insalubres a desarrollar. La representación de los estibadores se encuadraba en el Sindicato Único de Portuarios Argentinos (en adelante, SUPA), bajo la dirección de Eustaquio Tolosa. Este gremio se hallaba integrado por una heterogénea composición que incluía un numeroso sector de inmigrantes paraguayos $\mathrm{y}$ antiguos empleados desplazados del mundo industrial, entre otros. La sociabilidad obrera se producía por empresa, barco o lugar de descanso y comida (en las denominadas "ranchadas") y el tipo de contratación permitía a un despedido de una empresa encontrar trabajo para otra compañía. ${ }^{2}$ La representación de los trabajadores portuarios coexistía, además, con los sendos organismos que nucleaban, respectivamente, a los trabajadores carboneros, a los capataces y, por último, a los ayuntadores.

Con el inicio del "Onganiato", la ley 16.971, promulgada el 7 de octubre de 1966, creó el cargo de capitanes del puerto dando lugar a la aparición de funcionarios encargados de coordinar las distintas autoridades que coexistían en cada unidad portuaria (Aduana, Administración de Puertos, Junta de Granos y Carnes, Prefectura Marítima). Estos, además, actuarían como jueces en los problemas laborales cotidianos, decidirían sobre la

2. La huelga portuaria. Sus experiencias y enseñanzas, documento interno PRT, 1967. Archivo Fundación Pluma (AFP) http://fundacionpluma.info:8080/xmlui/ 
salubridad e insalubridad de cualquier bodega, las formas de trabajo y los conflictos de contratación. A su vez, la ley 16.972 disponía la habilitación de las instalaciones portuarias durante las 24 horas del día. Por último, el decreto 2.729 especificó las condiciones de labor y formas de pago. Las horas diarias se dividirían en turnos de seis horas, subdivididos a su vez en dos períodos de tres horas, con tres de descanso obligatorio. Este sistema imposibilitaba que el trabajador hiciera tiempos extras. A su vez, se imponían nuevos topes para el peso de las cargas (70 kilos la bolsa de cereales y 50 las de guano, cemento y piedra con un recorrido de 30 metros como máximo) lo que implicaba una alteración en cuanto a las nociones de insalubridad y límites impuestos a las lingadas antes existentes. ${ }^{3}$ Como resultado de ello, el aumento de la jornada laboral redundó en una reducción de un 33,33\% del tiempo improductivo de las embarcaciones en el puerto, la disminución en un $60 \%$ del costo de las operaciones portuarias y un $30 \%$ de incremento de la productividad. La estadía de un barco que, antes de la regimentación, permanecía diez días en un puerto, ahora reducía ese tiempo a la mitad merced a las nuevas cargas de trabajo (Tolosa, 1969).

Ante la aplicación de la política racionalizadora del gobierno, la dirección del SUPA, bajo el mando de Eustaquio Tolosa, encargada de la representación de los estibadores, apeló a entablar negociaciones y una estrategia de diálogo. El 19 de octubre, un día después de sostener una reunión con el propio Onganía,

3. Puertos: sobre el tejado de zinc caliente ( 18 al 24 de octubre de 1966). Primera Plana 199, pp. 16-18. Centro de Documentación e Investigación de la Cultura de Izquierdas (CeDInCI), Buenos Aires; La huelga portuaria. Sus experiencias y enseñanzas, documento interno PRT, 1967. el gobierno intervino este sindicato lo que redundó en el lanzamiento de la huelga por tiempo indeterminado. El desarrollo del conflicto, sostenido a lo largo de aproximadamente tres meses, tuvo oscilaciones y derivas en su dinámica. ${ }^{4}$

Como respuesta inicial a la intervención, los cuatro sindicatos del gremio portuario (estibadores, carboneros, capataces y ayuntadores) se plegaron al paro uniéndose, a su vez, en el Consejo Coordinador Intersindical con un programa de lucha que sostuvo la suspensión del reglamento de trabajo, la devolución del SUPA a sus legítimas autoridades y la convocatoria a una asamblea Intersindical como método para el hipotético levantamiento de la medida. Sin embargo, en la práctica, este organismo desempeñó un papel secundario y el propio Tolosa llevó a cabo una lógica que apeló a la solidaridad internacional y a la negociación como vías de resolución sin que mediara un sostenimiento de la huelga a partir de la organización de las bases portuarias y una coordinación de sus acciones. De hecho, apenas declarada la huelga, se retiró a Montevideo en la búsqueda de adhesión internacional.

A partir del estallido del conflicto y de su difusa centralización sindical, se visualizaron dos entidades organizativas de diversa índole. Por un lado, la formación de una Coordinadora de Agrupaciones Portuarias, integrada por los tres agrupaciones con injerencia entre los

4. El desarrollo del conflicto que se narra en los siguientes párrafos fue reconstruido por el autor para este trabajo a partir del seguimiento de los periódicos La Nación y Crónica y la revista semanal Primera Plana, como así también las publicaciones político-partidarias Nuestra Palabra, La Verdad y Política Obrera desde octubre de 1966 a enero de 1967. 
trabajadores portuarios: Justicia y Verdad (ligada a la conducción tolosista), Cruzada Renovadora (conformada por antiguos militantes trotskistas devenidos en una representación de la línea sindical representada por Augusto Vandor) y La Lingada (dirigida por el Partido Comunista). En los primeros días del conflicto, esta coordinación logró una cierta recaudación de fondos, edición de volantes y ligazón con una entidad estudiantilIntercentros- pero, tras los primeros diez días de huelga, perdió centralidad.

Por otro lado, se desarrolló un fenómeno de mayor significación: la organización de los activistas portuarios en los propios espacios de residencia, las villas y barrios populares del Gran Buenos Aires y la Capital Federal. Producto de ello, se produjo una paulatina conformación de Comisiones de Resistencia que, bajo metodologías asamblearias y división de tareas entre sus miembros, se transformaron en entidades fundamentales en el sostenimiento del conflicto a partir de acciones tales como la búsqueda de fondos mediante visitas a las fábricas de cada zona, la recolección de alimentos, los intentos de articulación con otros rubros, la edición de boletines y volantes y, específicamente, el afán por evitar y repeler el fenómeno más nocivo para el desarrollo de la huelga: la presencia de personal (denominado "carneros" o "rompehuelgas") que continuaban garantizando parte del funcionamiento portuario en el transcurso del conflicto.

En estos organismos territoriales tuvieron injerencia determinadas organizaciones revolucionarias más allá de no contar, en los momentos previos, con presencia en el espacio portuario como, por ejemplo, el PRT y Política Obrera (en adelante, PO), ambos de extracción trotskista. El fenómeno barrial no solo fue ignorado sino que, además, intentó ser absorbido por la dirigencia sindical a través de un intento de centralización de víveres desde las entidades gremiales tradicionales. Por ello, un componente de peso de este momento fue la tensión experimentada entre los organismos gremiales y aquellos territoriales surgidos en el transcurso de la lucha.

E1 conflicto fue sostenido hasta diciembre de ese año, básicamente a partir del papel desarrollado por las Comisiones de Resistencia que, paulatinamente, dieron forma a instancias de coordinación de sus acciones. En primer lugar, a través de la denominada Intervillas, que nucleó a aquellos representantes de los diversos comités y, posteriormente, a través del Secretariado de Intervillas transformado en la dirección, de hecho, de este movimiento territorial.

E1 paulatino desgaste de estos organismos fue evidente como así también la imposibilidad de detener fehacientemente el ingreso de rompehuelgas al ámbito portuario. Ante ese escenario, el 17 de diciembre, diversos gremios portuarios decidieron levantar el paro. Por su parte, en el marco de una asamblea de estibadores realizada por el SUPA en el Luna Park fue detenido Tolosa en plena deliberación dando lugar a una nueva medida de fuerza.

En un marco de retroceso, hacia finales de diciembre, la Intersindical de gremios portuarios levantó la huelga a condición de gestarse una mesa de negociación para rediscutir los cambios en las normativas del trabajo. Dada la política estatal implementada por el Capitán de puerto Mario Andrés Durriu, de impedir el ingreso a todos aquellos trabajadores que no gozaran de la libreta correspondiente otorgada durante la huelga 
(en la que se demostrara haber desempeñado tareas durante diez días en su transcurso), un mayoritario número de portuarios partícipes del conflicto quedaron legalmente relegados de la posibilidad de ejercer las funciones de estiba. Ello generó un pequeño resurgir de la conflictividad rápidamente apagada por la necesidad de reinsertarse laboralmente en otros rubros por parte de los portuarios.

Se sostiene como premisa que, a lo largo del derrotero descripto de este proceso y más allá de sus resultados, es factible identificar diversas características que son asimiladas al devenir de la conflictividad obrera emergida con posterioridad al Cordobazo pero que, como se vislumbra en este estudio de caso, ya se hallaban embrionariamente presentes en las características centrales de la lucha analizada. En este sentido, se identifican cuatro rasgos que marcarán su huella identitaria y que aparecen con frecuencia en las diversas muestras de conflictividad acaecidas años después.

\section{Heterogeneidad en las conducciones y disputas ínter-dirigenciales}

Como se mencionó, la dirección del conflicto se encontró a cargo del SUPA, bajo la conducción de Eustaquio Tolosa. Si bien el estibador se hallaba en condiciones de precariedad dado un trabajo marcado por irregularidades y falta de continuidad, la estructura sindical gozaba de privilegios que le habían permitido su consolidación económica. La puesta en práctica de una cooperativa de trabajo dirigida por el propio sindicato con facultad de contratación de mano de obra para las compañías navieras se convertía en un elemento central de recaudación a la vez que los servicios sociales ofrecidos se caracterizaban por su escasez. Por otro lado, resultaba escasa la representación de las diversas tendencias políticas ante la conformación de un cuerpo de ocho delegados elegidos directamente por la propia conducción. ${ }^{5}$

Con el lanzamiento del proceso de reformas portuarias, la dirección de Tolosa apeló a la negociación como modo de freno. Tras la obtención de una entrevista con el propio presidente el 18 de octubre, el gobierno dictaminó la intervención del sindicato lo que llevó al SUPA al lanzamiento de la huelga por tiempo indeterminado sin que mediara una organización previa a ella.

En el transcurso del conflicto, la dirección de Tolosa adoptó, centralmente, tres estrategias de intervención. En primer lugar, un desafortunado intento por sostener canales de negociación con las esferas gubernamentales. Así, mantuvo reuniones con el secretario de transportes, Antonio Lanusse, buscando la devolución al sindicato de la potestad de ordenar la alternación de los estibadores en el trabajo a cambio de la aceptación del sistema de cuatro turnos fijos. Por otro lado, en términos discursivos, Tolosa mantuvo una retórica que, sin negar la posibilidad de ejecutarse una reestructuración portuaria, ella debería surgir de una instancia de diálogo con la esfera sindical. ${ }^{6}$ Hacia medidos de diciembre,

5. La huelga portuaria. Sus experiencias y enseñanzas, documento interno PRT, 1967; La lucha portuaria (18 de enero de 1967). Politica Obrera-Boletín Quincenal, 10, pp. 7-15. CeDInCI, Buenos Aires.

6. CGT: guerra o paz con el gobierno (1 al 7 de noviembre de 1966). Primera Plana, 201, pp. 18-21; Portuarios: medidas de solidaridad internacional (22 de octubre de 1966). Crónica, p. 7. Hemeroteca - Biblioteca Nacional (HBN), Buenos Aires; Tolosa: ¿héroe o traidor? (6 al 12 de diciembre de 1966). Primera Plana 206, p. 13. 
el SUPA sostenía seis reivindicaciones como modo de resolución del conflicto: que no se tomaran represalias con los huelguistas tras un acuerdo; representación obrera en la bolsa de trabajo; formación de una comisión tripartita de empresarios, trabajadores y miembros del gobierno para redactar un reglamento de trabajo; garantizar los jornales mínimos convenidos; terminar con la intervención y restitución al gremio de la cooperativa de trabajo. ${ }^{7}$ La fallida asamblea que culminó con la detención de Tolosa se transformó en el momento más crítico de su conducción dado que ella se vislumbró como el intento de imposición de un principio de acuerdo con el gobierno y de cierre del conflicto que, en la práctica, daba cuenta de una dirección que no lograba transformarse en el canal de las tratativas ante un oficialismo que aspiraba no solo a levantar el paro sino también a evitar el retorno del activismo a sus tareas y erradicar determinados derechos de sus trabajadores. ${ }^{8}$

En segundo orden, la conducción del SUPA apeló a la vía judicial lo que conllevó un éxito relativo dado que, a través de un recurso de amparo, el juez de trabajo, José Francisco D'Hers exhortó a los huelguistas a cesar con las medidas de fuerza instando, a su vez, a que el Estado transfiriese a su tribunal la intervención del sindicato. Esto se reveló insuficiente dado que el gobierno no avaló la resolución ni acudió a la audiencia de conciliación a la vez que declaró, a través del ministro de Trabajo Jorge Salimei que no se revisaría ninguna medida adoptada con anterioridad. ${ }^{9}$

7. Ni vencedores ni vencidos (20 al 26 de diciembre de 1966). Primera Plana 208, pp. 16-18.

8. La lucha portuaria (18 de enero de 1967). Política Obrera 10, pp. 7-14.

9. Gremios: La espada de Damocles (29 de noviembre al 60
Por último, la principal acción gestada por el SUPA consistió en la apelación a la solidaridad internacional. Apenas iniciado el conflicto, Tolosa viajó a Montevideo para reunirse con Manuel Medrano, director regional de la Federación Internacional de Trabajadores del Transporte (ITF) exhortando a los sindicatos portuarios del mundo a sostener un boicot internacional a las embarcaciones argentinas. ${ }^{10}$ Finalmente,el 2 de noviembre,la ITF comunicó su realización efectiva a buques argentinos en América Latina y el Caribe y, el día 18, dispuso desde Londres el boicot internacional (el cual sostuvo formalmente hasta el 12 de diciembre aludiendo al inicio de negociaciones entre los portuarios argentinos y su gobierno). ${ }^{11}$ Uruguay y Chile fueron los países en los que mayormente se aplicó la solidaridad con el conflicto argentino. En Uruguay, la Unión Solidaria de Obreros Portuarios realizó un paro de actividades el día 4 en solidaridad y envío una delegación a la Argentina exigiendo una reunión con Onganía. Sistemáticamente, durante el siguiente mes, diversas embarcaciones argentinas quedaron varadas en el puerto sin lograr realizar la descarga de mercaderías. ${ }^{12}$ Similar situación se experimentó

5 de diciembre de 1966). Primera Plana 205, pp. 13-16; No habrá representantes oficiales en la audiencia (20 de noviembre de 1966). Crónica, p. 3.

10. Gremios: El tamaño de una rebelión (22 al 28 de noviembre de 1966). Primera Plana 204, p. 14.

11. Portuarios: la ITF dispuso boicot internacional (18 de noviembre de 1966). Crónica, p. 17; Fue levantado el boicot internacional (13 de diciembre de 1966). Crónica, p. 15; En ningún puerto rige el boicot a las naves argentinas (13 de diciembre de 1966). La Nación, pp. 1 y 20. HBN, Buenos Aires.

12. Transportes: $\mathrm{El}$ viernes empezará a efectivizarse el boicot mundial (2 de noviembre de 1966). Crónica, p. 10; Los trabajadores portuarios de Montevideo realizan hoy un paro (3 de noviembre de 1966). Crónica, p. 8; Efectivizarán el miércoles el paro de transportes (4 de 
en Chile durante 15 días, principalmente en el puerto de Valparaíso, ante las acciones de boicot desarrolladas por la Confederación Marítima de Chile. ${ }^{13}$ En menor medida, se identifican muestras de apoyo en Venezuela, Colombia, Finlandia, Italia (en el puerto de Génova) y EE.UU, en donde la Amalgamated Union Transit envió una nota de apoyo a los portuarios dirigida a Onganía, la Asociación Ejecutiva Gremial Railway votó un apoyo a los sindicatos argentinos del transporte y la Asociación Internacional de Estibadores (con sede en Nueva York), discutió la posibilidad de un boicot mundial a los buques argentinos en apoyo a sus portuarios. ${ }^{14}$

La intervención de la ITF en el conflicto fue directa desde diciembre a través de la figura de Manuel Medrano y la realización de reuniones con el secretario de Trabajo, Rubens San Sebastián. Aparentemente, como producto de estas tratativas, el gobierno se comprometió a levantar la intervención del SUPA llamando a

noviembre de 1966). Crónica, p. 19; Inician hoy el boicot los portuarios uruguayos (11 de noviembre de 1966). Crónica, p. 15; Paralizan las operaciones de 2 buques argentinos en Uruguay (12 de noviembre de 1966). Crónica, p. 16; Aconsejó el boicot la IT (17 de noviembre de 1966). Crónica, p. 19; Portuarios uruguayos levantaron el boicot a los barcos argentinos (10 de diciembre de 1966). Crónica, p. 8.

13. "En Chile fueron boicoteadas tres naves argentinas", en: Crónica, 06-11-1966, p. 4

14. Efectivizarán el miércoles el paro de transportes (4 de noviembre de 1966). Crónica, p. 19; Transportes: Comenzó el paro en toda la república ( 9 de noviembre de 1966). Crónica, p. 9; Paralizan las operaciones de 2 buques argentinos en Uruguay (12 de noviembre de 1966). Crónica, p. 16; Aconsejó el boicot la ITF (17 de noviembre de 1966). Crónica, p. 19; Afectó las tareas ferroviarias y marítimas el paro de transporte (10 de noviembre de 1966). Crónica, p. 8; Sobre Tolosa aún no decidió nada el gobierno de Uruguay (9 de diciembre de 1966). Crónica, p. 5. elecciones en un plazo de 90 días, analizar la formación de la bolsa de trabajo con la garantía de un mínimo de jornales para el estibador y la creación de una comisión tripartita que estudiaría el reglamento. Ello motivó el levantamiento de la huelga por parte de los apuntadores, carboneros y capataces dejando al SUPA en un relativo aislamiento. No obstante, la nueva reglamentación implementada, que incorporaba la necesidad de una credencial plástica para acreditar la realización de diez días de trabajo durante la huelga, restringía a los portuarios partícipes a retomar sus tareas. Las gestiones autónomas por parte de la IFT y el levantamiento del boicot internacional habrían sido factores que desgastaron la relación entre Tolosa y la entidad internacional. ${ }^{15}$

Con respecto a los restantes sindicatos portuarios, en los momentos iniciales, existió la coordinación de las cuatro entidades portuarias (estibadores, carboneros, capataces y ayuntadores) a través del Consejo Coordinador Intersindical. En la práctica, al establecerse una tentativa de acuerdo, cada sindicato resolvió de modo autónomo el cese de su participación en el conflicto en sendas asambleas de sus respectivos afiliados. De hecho, al iniciarse la fallida asamblea de estibadores en el Luna Park que redundaría en la detención de Tolosa, los tres sindicatos portuarios restantes ya habían resuelto el levantamiento de la huelga. ${ }^{16}$

15. Portuarios (23 de enero de 1967). La Verdad, 74, pp. 3 y 6. AFP http://fundacionpluma.info:8080/xmlui/ ; Ni vencedores ni vencidos (20 al 26 de diciembre de 1966). Primera Plana 208, pp. 16-18; Portuarios: optimismo para solucionar el pleito (16 de diciembre de 1966). Crónica, p. 10; Portuarios: hay bases de solución (17 de diciembre de 1966). Crónica, p. 8.

16. Levantan el paro tres sindicatos portuarios; el SUPA se reúne hoy (18 de diciembre de 1966). Crónica, p. 8. 
Un elemento de relieve que atravesó al conflicto recayó en las internas inherentes a sus dirigencias partícipes y a la existencia de una lógica de disputa ínter-dirigencial encuadrada en las tensiones que la Confederación General del Trabajo (en adelante, CGT) experimentaba desde el golpe(Schneider,2005).Laconducción de la CGT, asumida en octubre de 1966 y a cargo de un lugarteniente de Augusto Vandor, Francisco Prado, se hallaba en una dinámica de expectativa e intento de negociación con la flamante dictadura. El estallido del conflicto la hizo entrar rápidamente en tensión con la conducción del SUPA ante lo que este sindicato entendió como la carencia de un respaldo de peso. En su congreso de los días 21 y 22 de octubre, la CGT rechazó la posibilidad de responder con un paro general al reglamento de trabajo portuario y optó por apelar a la voluntad negociadora del gobierno. Presionada por las exigencias de los portuarios a través de la Confederación Argentina de Trabajadores del Transporte (en adelante, CATT) y por la posibilidad de que este tipo de reglamentación se trasladara a otros rubros, la CGT trató el conflicto con el secretario de Trabajo en una reunión el 2 de noviembre. Aunque formalmente interrumpido, el diálogo continuó luego por vías subterráneas lo que generó, incluso, tensiones dentro del propio gobierno de facto (por ejemplo, entre el mencionado funcionario y el interventor del SUPA, el capitán de fragata, Felipe Gardella quien terminó siendo desplazado por el civil Victorino Vidal y se convirtió en un interlocutor de la central obrera). En diversos encuentros, Vandor ofreció como resolución a la crisis que la intervención del SUPA pasara a manos de la CGT para traspasar luego su conducción a un núcleo de dirigentes tolosistas (ante la partida del país de su responsable) que aceptarían el nuevo código de trabajo. Según La Nación, las reuniones entre la CGT y las autoridades nacionales se entorpecieron por el boicot internacional declarado a las embarcaciones argentinas lo que ubicó a la central en una situación incómoda dado que, se presentaba como mediadora sin tener la capacidad plena de dar una resolución al problema. ${ }^{17}$

Por otra parte, ante la presión portuaria y la amenaza de la extensión del conflicto a los rubros ferroviario y azucarero, la CGT se vio obligada a convocar a un paro general el 14 de diciembre y, luego del mismo, llamó a una reunión del Comité Central Confederal de la CGT para evaluar la situación. La mayoría de sus miembros insistieron en la necesidad de mantener una expectativa positiva hacia el gobierno nacional proponiendo que la central obrera se integrara a unas hipotéticas "comisiones oficiales para el estudio de determinadas leyes". En dicho encuentro, los representantes portuarios Eustaquio Tolosa y Telmo Díaz rechazaron la estrategia dialoguista de la conducción de la central. ${ }^{18}$

17. CGT: guerra o paz con el gobierno (1 al 7 de noviembre de 1966). Primera Plana 201, pp. 18-21; El muelle de las brumas (8 al 14 de noviembre de 1966). Primera Plana 202, p. 15; Angustias de un querer (15 al 25 de noviembre de 1966). Primera Plana 203, p. 24; Gremios: El tamaño de una rebelión (22 al 28 de noviembre de 1966). Primera Plana 204, p. 14; Avance histórico: comienzo del surgimiento de una dirección clasista (14 de noviembre de 1966). La Verdad 66, pp. 1-9; En el pleito de los portuarios se definieron bases (18 de noviembre de 1966). La Nación, pp. 1 y 20.

18. Dispuso la CGT realizar el 14 un paro general (2 de diciembre de 1966). La Nación, pp. 1 y 20; Gremios: La espada de Damocles (29 de noviembre al 5 de diciembre de 1966). Primera Plana 205, pp. 13-16; El éxito del paro demuestra que la clase obrera enfrenta a la dictadura (20 de diciembre de 1966). Nuestra Palabra 858, pp. 3-4. CeDInCI, Buenos Aires. 
No obstante, el momento más álgido de tensión entre ambas entidades se visualizó el 20 de diciembre cuando un grupo de portuarios ocupó las instalaciones de la CGT denunciando su pasividad. La conducción cegetista, en la firma del dirigente de la carne, Eleuterio Cardoso, emitió un comunicado repudiando la ocupación y afirmando que ella no tenía que ver con los trabajadores portuarios verdaderos siendo una "burda provocación realizada por enemigos de la clase trabajadora". Ante la amenaza gubernamental de desalojo por la fuerza, la central se desocupó dos días después. Si bien no reivindicado por la propia conducción del SUPA, diversas expresiones de las izquierdas consideraron que se trató de una acción aislada para proteger su imagen ante una derrota inminente atribuyendo la problemática principal al débil papel cumplido por la central. Prado, por su parte, argumentó que consistió en una provocación con el objetivo de desatar el accionar policial y una escalada de violencia que justificara la intervención de la CGT. ${ }^{19}$

\section{Embrionaria dualidad de los organismos de lucha mediante la vinculación del mundo obrero con el ámbito territorial}

Uno de los fenómenos más originales desarrollados en el derrotero del conflicto fue la proliferación de órganos de deliberación y resolución que aglutinaron a los trabajadores portuarios, no en el marco de sus entidades sindicales sino en el ámbito territorial a

19. Portuarios siguen ocupando la CGT. Plenario secreto de 72 gremios. (21 de diciembre de 1966). Crónica, pp. 10-11; La CGT fue desalojada por fuerzas policiales anoche (22 de diciembre de 1966). La Nación, pp. 1 y 16; La lucha portuaria (18 de enero de 1967). Política Obrera 10, pp. 7-15; Una nueva asamblea de portuarios prohibióse (23 de diciembre de 1966). La Nación, p. 12. partir de la gestación de instancias barriales de organización radicadas en las villas de la Capital Federal y ciertos núcleos de la provincia de Buenos Aires en donde residía un porcentaje elevado de los estibadores. Se trató de un movimiento ascendente que comenzó con la formación de Comisiones de resistencia focalizadas en diversos barrios, inicialmente cercanos a la zona portuaria para luego proliferarse hacia el Conurbano bonaerense. Los organismos gestados en Retiro, Dock Sud, Villa Jardín, Burzaco, Solano, Claypole, Barrio paraguayo de Berazategui, Barrio Rivadavia, Isla Maciel, Villa Corina, Villa Celina, Almirante Brown, Barrio Sarmiento, Ingeniero Budge, Villa Agüero son algunos de los ejemplos más dinámicos de un fenómeno que, se estima, superó las 40 Comisiones de resistencia con una composición que osciló los cien miembros y adherentes en cada una y en las que primó el método asambleario.

En sus inicios, las actividades de estas comisiones se circunscribieron a la recolección de dinero, alimentos y medicación para los obreros en huelga y sus familias. La visita de integrantes de estas comisiones a fábricas de las zonas o a asambleas de trabajadores de otros rubros (prioritariamente, ferroviarios) para buscar la colaboración económica y la solidaridad con el conflicto portuario; la realización de campeonatos de fútbol y bochas; el impulso de rifas semanales o festivales artísticos; la organización de proveedurías y ollas populares, entre ejemplos, fueron parte del repertorio desarrollado por las respectivas Comisiones en la búsqueda de fondos que le permitieran al trabajador en huelga sostenerse financieramente. Paulatinamente, en distintos organismos barriales, comenzó a priorizarse como tarea central la búsqueda de un freno a la presencia de una considerable cantidad 
de personas que, independientemente del conflicto, garantizaron las tareas de estibaje. La visita e intimidación a las casas de los "rompehuelgas" (o carneros) o la aplicación de medidas de acciones violentas contra ellos fueron también un componente de estas entidades. En menor medida, algunas comisiones dieron forma a "comisiones de mujeres" que tomaron tareas como recolectar fondos y recorrer las casas de los vecinos de los "rompehuelgas" para explicarles que, en caso de quemarse la vivienda de uno de ellos, se corría el riesgo de un incendio en toda la villa. ${ }^{20}$

Una de las expresiones de mayor interés de este proceso recayó en la gestación de una entidad coordinadora de estas experiencias, la Coordinadora de las Comisiones de Resistencia de Villas y Barrios, también denominada Intervillas, formada a principios de noviembre. Con la influencia más o menos soslayada de diversas organizaciones partidarias, el paso hacia la construcción de una coordinación fehaciente de las diversas entidades barriales obedeció, en primer lugar, a la caracterización de un sindicato paralizado para garantizar el avance del proceso de lucha y, en otro orden, para forjar el paso de una etapa defensiva (consistente en la recolección de alimentos y supervivencia de

20. No hay 'pacto social': pararon los trenes, los barcos y los puertos (15 de noviembre de 1966). Nuestra Palabra 853, p. 3; Portuarios: fracasan las recetas de la dictadura (29 de noviembre de 1966). Nuestra Palabra 855 , p. 3; Paro de 24 horas en solidaridad con los obreros portuarios (6 de noviembre de 1966). La Verdad 65, pp. 1-7; Boletín $\mathrm{N}^{\circ} 1$ de la Coordinadora de Comités de Resistencia de Villas y Barrios (CRVB). (noviembre de 1966). AFP http://fundacionpluma.info:8080/xmlui/; Boletín de Huelga 2 (15 de noviembre de 1966). CRVB; Dos tendencias desde la primer reunión del Secretariado (1966). Comité Central del PRT. AFP; Boletín de huelga 3 (15 de noviembre de 1966). CRVB; Boletín de Huelga 11(9 de diciembre de 1966). CRVB.

64 los huelguistas) a una ofensiva que priorice el accionar contra los rompehuelgas. En su reunión fundacional, Intervillas aprobó como tareas la concurrencia a la CGT para obtener el reconocimiento del organismo; la búsqueda de extensión del conflicto con volantes a otros rubros; estudiar quiénes eran los rompehuelgas en cada barrio; y ayudar a la conformación de nuevas Comisiones de resistencia en cada villa. A la vez, eligió un Secretariado de Intervillas, conformado por seis miembros, para la centralización de tareas. ${ }^{21}$ A lo largo de ese mes, Intervillas se nutrió de un mayor número de representaciones barriales. En sus inicios, planificó acciones para garantizar el paro de transportes convocado el 9 de noviembre; visitó diversas seccionales ferroviarias en busca de apoyo y editó un boletín de huelga regular para reflejar las actividades realizadas por cada villa, narrar la marcha del conflicto y exponer a los rompehuelgas mediante la publicación de sus nombres y direcciones. ${ }^{22}$ Por su parte, la elección de un Secretariado (el cual mutó en su composición) pretendió transformarse en una instancia de coordinación estructural que, entre otras tareas, ayudara a organizar las comisiones de alguna villa (o bien, reforzarla) a través del envío de estudiantes involucrados en el conflicto; asesorar y coordinar el trabajo de las diversas villas; $y$ difundir determinadas informaciones. ${ }^{23}$

Se afirma la existencia de una dualidad de poderes en los organismos de lucha dado que

21. Acta de la reunión del día 6 de noviembre de 1966 (noviembre de 1966). CRVB.

22. Boletín de Huelga 2 (15 de noviembre de 1966).

CRVB; Boletín de Huelga 4 (22 de noviembre de 1966). CRVB.

23. Boletín de Huelga 4 (22 de noviembre de 1966). CRVB. 
estas entidades territoriales que pugnaron por el sostenimiento del conflicto se desarrollaron en simultaneidad a los organismos sindicales tradicionales y a la dinámica de sus agrupaciones portuarias en una coexistencia no carente de tensiones. En su conformación, Intervillas afirmó la necesidad de mantener un diálogo permanente con el SUPA y con la Coordinadora de agrupaciones portuarias reconociendo, a su vez, a la Intersindical portuaria e instando a que los dirigentes de los estibadores participaran de los organismos de base a la vez que sean aceptadas estas flamantes entidades. En las primeras semanas de noviembre, el Secretariado de Intervillas se reunió en tres oportunidades con dirigentes del SUPA para acercarles la propuesta de trabajo en común. ${ }^{24}$

Expresión de esta dualidad fue la creación del Consejo del Estibador, un organismo creado a instancias del SUPA ante la aparición de Intervillas, conformado por 27 miembros representantes del sindicato, 12 miembros de las agrupaciones portuarias y 12 delegados del movimiento de las comisiones de resistencia barriales. Así, el peso de estas nuevas entidades territoriales quedaba diluido ante las anteriores instancias de participación. Por otro lado, en dicho organismo se instó a los delegados enviados por a las villas a realizar tareas de recolección de vidrios, botellas y trapos viejos para recaudar fondos, a la vez que se dictaminó que la dirección del sindicato era la única con potestad para autorizar o no cualquier tipo de campaña financiera lo que, en la práctica, coartaba la posibilidad de editar bonos para su venta en fábricas o realizar eventos en

24. Avance histórico: comienzo del surgimiento de una dirección clasista (14 de noviembre de 1966). La Verdad 66, pp. 1-9; Boletín1.(noviembre de 1966) CRVB;

Boletín de Huelga 2 (17 de noviembre de 1966). CRVB. un barrio. En el transcurso de los hechos, la dirección del SUPA obstaculizó la labor de los comités de resistencia frenando el envío de víveres a los barrios en los que funcionaran comisiones cuya orientación no controlara (bajo el argumento de que su distribución debía centralizarse desde las regionales de la CGT habilitadas). Finalmente, se produjo la ruptura definitiva cuando, el 15 de noviembre, el SUPA se negó reconocer la participación de estudiantes en las comisiones de resistencia y en las medidas a desarrollar. ${ }^{25}$

La pervivencia de la dualidad de organismos se reveló insostenible, no solo ante el papel desempeñado por una dirigencia sindical que primero ignoró a los organismos territoriales para luego obstaculizarlos sino también porque la propia dinámica del conflicto, en un claro desgaste, llevó a sus participantes a la búsqueda de otras tareas laborales y al paulatino abandono del compromiso militante. En la práctica, la organización barrial se convirtió en una herramienta simultánea y no en el reemplazo de la dirección gremial existente. Tras levantarse la huelga, la última acción clara impulsada por Intervillas recayó en la asistencia al puerto para obstaculizar el ingreso al trabajo de quienes gozaban de la nueva libreta reglamentaria tras haber desarrollado tareas laborales los días de paro. ${ }^{26}$

Como se mencionó, una primera aproximación al fenómeno territorial acaecido durante este conflicto fue descripta por Snitcofsky

25. Desgrabación del CC del 17 de diciembre de 1966

(17 de diciembre de 1966). Comité Central del PRT

AFP; Se negocia a espaldas del gremio (21 de noviembre de 1966). La Verdad 67, pp. 1-3 y 14; Boletín de huelga 3 (15 de noviembre de 1966). CRVB.

26. Boletín de Huelga 15 (29 de diciembre de 1966). CRVB. 
(2011). No obstante, su trabajo es proclive a pensar cómo diversas prácticas y métodos adquiridos en el mundo del trabajo fueron luego trasladados al ámbito territorial. Si bien este enfoque es válido, en el caso portuario en particular se revela parcial. Como se verá en el último apartado, el origen y la dinámica de estos organismos territoriales no logra explicarse por la anterior pertenencia al mundo obrero de sus protagonistas sino, centralmente, por la presencia de determinadas organizaciones políticas (centralmente, del campo de las izquierdas) que imprimieron su huella $\mathrm{y}$ determinaron el derrotero de estas instancias de participación cuando, ante la imposibilidad de una militancia férrea en el propio sitio de trabajo, trasladaron su estrategia de inserción y participación al espacio barrial.

\section{Esbozos de solidaridad en el mundo del trabajo y en la coordinación con el estudiantado}

Un limitante para el sostenimiento y posibilidad de triunfo portuario recayó en las dificultades para forjar una vinculación fehaciente y acciones en común con otros núcleos del mundo del trabajo. En la práctica, desde el inicio de la huelga, la CATT se declaró el estado de alerta en sus gremios asociados y solicitó una audiencia con Onganía logrando una entrevista con el secretario de Trabajo. La decisión de este organismo de convocar a un paro de transporte en solidaridad con los portuarios no estuvo exenta de debates dada una tendencia interna que argumentaba la necesidad de dilatar la medida hasta agotar las negociaciones. Finalmente, el 9 de noviembre, se efectuó el paro de transportes con la adhesión de la Unión Ferroviaria y La
Fraternidad pero no así de la Unión Tranviarios Automotor (limitándose a un comunicado de apoyo público) ni de la Asociación Argentina de Aeronavegantes. ${ }^{27}$ Por su parte, las 62 Organizaciones, declamatoriamente, dieron a conocer el día 8 de noviembre una declaración de apoyo llamando a las autoridades a encontrar una solución inmediata al conflicto y reclamando la intervención directa del presidente. ${ }^{28}$ Días antes, la conducción de la CGT se reunió, sin éxito, con el secretario de Trabajo. Tras el anuncio del paro de transportes, la central oficializó el final de su papel como intermediario en el conflicto. ${ }^{29}$

Un rubro buscado y potencialmente aliado del portuario fue el del gremio ferroviario dado que también pesaba sobre él la posible iniciativa de una lógica de racionalización por parte del Estado. Horas después del paro de la CATT, las seccionales Chacarita, Once, Liniers, Colegiales, San Martín, Boulogne y Villa Lynch realizaron un plenario y resolvieron requerir a la Comisión Directiva de la Unión Ferroviaria un giro inmediato de fondos de ayuda para los huelguistas portuarios además de instar a su conducción a la realización de un acto público de denuncia de los planes gubernamentales. La seccional de Villa Lynch,

27. Puertos: sobre el tejado de zinc caliente (18 al 24 de octubre de 1966). Primera Plana 199, pp. 16-18; La Intersindical de los portuarios dispuso una huelga general por tiempo indeterminado (19 de octubre de 1966). Crónica, p. 16; Harían un paro el 28 los gremios del transporte (25 de octubre de 1966). Crónica, p. 10; Transportes: Comenzó el paro en toda la república (9 de noviembre de 1966). Crónica, p. 9.

28. Transportes: Comenzó el paro en toda la república ( 9 de noviembre de 1966). Crónica, p. 9; Portuarios: piden la intervención de Onganía (22 de noviembre de 1966). Crónica, p. 15.

29. Efectivizarán el miércoles el paro de transportes (4 de noviembre de 1966). Crónica, p. 19. 
incluso, sostuvo un paro de 24 horas tras una asamblea general extraordinaria. ${ }^{30} \mathrm{~A}$ su vez, aunque excepcional, la documentación da cuenta de la conformación de una Comisión de resistencia ferroviaria-portuaria integrada por miembros de la Unión Ferroviaria de Chacarita y representantes de la Comisión de Resistencia de la villa más cercana. ${ }^{31}$

Por medio de asambleas, diversos rubros y ámbitos de trabajo brindaron su apoyo a los estibadores como, por ejemplo, los empleados de Alpargatas o los gremios telefónico, químico y maderero como así también agrupaciones particulares de una empresa como El Activista de la Carne de los frigoríficos ArmourSwift de la localidad de Berisso. Todas estas parecen haber sido, centralmente, iniciativas desarrolladas por el activismo de las izquierdas insertas en los respectivos rubros. ${ }^{32}$ Por ende, un nítido límite del conflicto portuario se circunscribió a la ausencia de una férrea articulación entre diversos rubros, incluyendo a aquellos más apremiados por la deriva racionalizadora del "Onganiato".

En simultáneo, una característica destacada del conflicto recayó en la presencia de una destacada solidaridad por parte del movimiento estudiantil universitario. En su derrotero, se produjo la conformación de un organismo de

30. No hay 'pacto social': pararon los trenes, los barcos y los puertos (15 de noviembre de 1966). Nuestra Palabra 853, p. 3; Boletín de Huelga 2 (15 de noviembre de 1966). CRVB.

31. Boletín de huelga 4 (22 de noviembre de 1966). Coordinadora de Comisiones de Resistencia de Intervillas (CCRI).

32. Portuarios: fracasan las recetas de la dictadura (29 de noviembre de 1966). Nuestra Palabra 855, p. 3; Informe sobre Berisso, PRT, 1967. AFP; ¿Con el gobierno o con los compañeros portuarios (20 de octubre de 1966). Volante de El Activista de la Carne, PRT, Berisso. AFP. representación estudiantil, Intercentros, con el fin de forjar una vinculación con el gremio portuario. El movimiento estudiantil se ligó a la huelga a través de diversas acciones: colaborar en la realización de fondos de huelga a través de bonos y colectas; reparto de volantes en las villas; puesta en práctica de actos relámpagos y pintadas para difundir el conflicto; visitas de delegaciones estudiantiles a ferroviarios y trabajadores de la carne en la búsqueda de solidaridad, fueron parte del repertorio desarrollado. Estas actividades se hallaron, mayoritariamente, vinculadas a la dinámica adoptada por las corrientes de izquierda insertas en el conflicto. En el caso de aquellos estudiantes fehacientemente vinculados a ellas, fue regular la práctica del pernocte y residencia temporaria en las villas para formar parte de las diversas acciones que la huelga imponía desde horas tempranas de la mañana. ${ }^{33}$ En el transcurso de la huelga, en algunas instituciones universitarias se dieron forma a comisiones de relación obreroestudiantiles que tomaron específicamente como temática la participación en ella. ${ }^{34}$

Inicialmente, existió una cierta ligazón entre Intercentros y la Coordinadora de agrupaciones portuarias. De hecho, se dan cuenta de algunos volantes firmados por ambas entidades. ${ }^{35}$ Paulatinamente, y a partir de la injerencia de

33. Negocian el boicot internacional a los buques y aviones argentinos (24 de octubre de 1966). Crónica, p. 4; Boletín de informaciones (31 de octubre de 1966). PRT.

34. Boletín de la Comisión de Relaciones Obrero Estudiantiles del Centro de Estudiantes de Ciencias Naturales (CECN) nro. 1 (23 de noviembre de 1966). AFP.

35. A los compañeros trabajadores. Paro total el 9 de noviembre (noviembre de 1966). Volante de Coordinadora de Agrupaciones e Intercentros de Estudiantes. AFP. 
las izquierdas, la vinculación del movimiento estudiantil se afianzó prioritariamente a través de los comités de resistencia barriales y en la conformación de Intervillas. En estas instancias, el activismo estudiantil fue aceptado como parte integrante, más allá de la existencia de ciertas discusiones. ${ }^{36}$ Se destaca, en este sentido, la participación estudiantil de diversas agrupaciones, directa o indirectamente ligadas al PRT, como UPE de Farmacia y Bioquímica; UAP de Filosofía y Letras; FAP de Derecho; FAA de Ciencias Naturales; FELNA de Ciencias Exactas; VUM de Medicina ${ }^{37}$; el activismo estudiantil de Política Obrera y, en menor medida, de Vanguardia Comunista. A la vez, se da cuenta de diversos modos de involucramiento por parte de agrupaciones de tradición peronista como el Frente Estudiantil Nacional (FEN) que emitió comunicados de solidaridad hacia los portuarios y de apoyo a la toma de la CGT en repudio a la pasividad de su conducción ${ }^{38}$ y del Movimiento Universitario Popular (MUP) de la Facultad de Derecho de la UBA (Saidón, 2005).

\section{El papel de las izquierdas en el sostenimiento de la conflictividad}

Un último elemento de calibre recayó en la existencia de una retroalimentación entre el movimiento portuario en lucha y las organizaciones pertenecientes al campo de las

36. Avance histórico: comienzo del surgimiento de una dirección clasista (14 de noviembre de 1966). La Verdad, 66, pp. 1-9.

37. Solidaridad con los portuarios en huelga ( $20 \mathrm{de}$ octubre de 1966). Volante, PRT. AFP.

38. Reacciones en distintos sectores por el procedimiento inesperado. La detención de Tolosa origina comentarios (21 de diciembre de 1966). Crónica, p. 11. izquierdas que pugnaron por lograr una política de involucramiento en el conflicto. Si bien es certera la noción que indica que el crecimiento de estas corrientes se vislumbró con claridad luego del Cordobazo, resulta de interés hacer notar que, en los inicios de la autodenominada Revolución Argentina, existió una inserción de diversas organizaciones autodefinidas como revolucionarias en la conflictividad laboral que enfrentó el plan racionalizador.

En el relevo historiográfico mencionado, Schneider sostuvo que, además de su prolongada extensión, el rasgo más significativo de la protesta fue que esta se encontró encabezada por una conducción independiente de la conducción del sindicato representada por los Comités de Resistencia barriales. En la misma línea, Valeria Snitcofsky reconstruyó esta experiencia dando cuenta de su dinámica en estos meses (Schneider, 2005 y Snitcofsky, 2011). No obstante su valor, este análisis omite un factor de relieve. Resulta una mirada incompleta y parcial reflexionar sobre la dinámica de estas entidades de construcción territorial si se deja a un lado la participación de diversas expresiones del campo de las izquierdas. Se sostiene como hipótesis que su involucramiento fue un componente fundamental para el proceso de gestación y desarrollo de estos organismos y, en razón de ello, para comprender la prolongación de un conflicto que excedió a los órganos sindicales tradicionales.

Entre las propuestas de izquierda, el peso central estuvo dado por las organizaciones de ideología trotskista. Tanto para el PRT (fundado un año antes) como para el PO (conformado en 1964), la lucha portuaria se convirtió en el primer ejemplo concreto de peso en cuanto al intento de vinculación 
fehaciente con un proceso huelguístico de larga duración al que volcar sus núcleos de militancia pugnando por una injerencia.

E1 PRT carecía de presencia previa en el rubro pero, en el transcurso de la huelga, se transformó en una de las corrientes más activas. Destinó alrededor de veinte militantes abocados al conflicto de modo permanente, incluyendo a tres miembros de su Comité Ejecutivo, a los respectivos responsables de los equipos de Avellaneda y de Zona Norte de Buenos Aires y a diversos referentes del movimiento estudiantil. Desde el inicio, se impuso como tarea central la organización de comisiones de lucha en las villas. Transcurrida una semana, contó con injerencia en Comités de lucha de cinco villas (centralmente, en Villa Jardín) y, en el transcurso del conflicto, colaboró en la conformación de alrededor de veinte Comités. Una táctica para forjar esta vinculación fue instar a la militancia involucrada a residir temporalmente en ese espacio. ${ }^{39}$

Como método de inserción, este partido desarrolló variantes según ya existiera o no un Comité de lucha en una villa. En caso de tratarse de un espacio sin organización, sus militantes utilizaron el recurso de establecer contacto con sus residentes presentándose como obreros o estudiantes vinculados a la huelga mediante la Coordinadora o Intercentros, dejando de lado la filiación partidaria. Si ya existía un organismo creado, la estrategia recaía en ponerse a disposición de dicha organización para las tareas que fueran necesarias desarrollar también manteniendo inicialmente anónima la identidad. Una vez establecidos los vínculos, impulsó tareas de

39. Desgrabación del CC (17 de diciembre de 1966). Comité Central del PRT, p. 10; Boletín de informaciones (31 de octubre de 1966). PRT, pp. 1 y 5 . AFP. distinta índole. Por un lado, pugnó por la realización de actividades básicas tales como la recolección de alimentos y la formación de un fondo de huelga (mediante acciones como la búsqueda de ayuda económica o la visita a las fábricas de la zona con bonos de contribución). En la misma línea, intentó organizar una proveeduría en alguna casa para el reparto de víveres; la confección de listados de domicilios de los obreros de la villa y de la zona para realizar visitas diarias y así sumar voluntades al conflicto como, a su vez, la concurrencia a las viviendas de aquellos que no se adherían a la huelga con el objeto de revertir esta actitud. A lo largo del proceso, colaboró con la edición del boletín de huelga de las comisiones de las villas. ${ }^{40}$ Como corolario, este partido pasó a convertirse en la organización más influyente en el lanzamiento y posterior derrotero de Intervillas. ${ }^{41}$

A la vez, se volcó de un modo consistente a través de su brazo estudiantil. El balance de esta experiencia indica que, finalmente, se transformó en uno de los animadores del movimiento de apoyo gestado desde las villas. De hecho, en diversas instancias de deliberación y coordinación, ya sea con la CGT o con la coordinadora de agrupaciones del SUPA, un militante de este partido, Oscar Prada, concurría como representante de Intervillas. ${ }^{42}$ Otra expresión de esta presencia recayó en que el boletín de huelga de Intervillas fue realizado en la imprenta de este partido. A la vez, el PRT desarrolló la difusión e intento de ligazón con

40. Informe de actividades (1966). III Congreso del PRT, p. 6. AFP.

41. La lucha portuaria (18 de enero de 1967). Política Obrera 10 , pp. 7-15.

42. Informe de actividades (1966). III Congreso del PRT, p. 6. AFP. 
el conflicto desde el ámbito universitario a través de diversas agrupaciones en Farmacia y Bioquímica, Filosofía y Letras, Derecho y Ciencias Naturales, entre otras. ${ }^{43}$

Con el correr del paro, el PRT reorientó sus prioridades. Dejó en un segundo plano la práctica de recolección de alimentos y ayuda económica a los huelguistas para privilegiar el desarrollo de acciones como el enfrentamiento contra los rompehuelgas y la recolección de dinero que garantizara la defensa contra la represión y los viáticos de los activistas. Se destaca la planificación de métodos aplicados como la fabricación de "miguelitos" y de artefactos explosivos caseros y la logística para enfrentar a los rompehuelgas. ${ }^{44}$ Por otra parte, en la medida en que contribuyó a la formación de Comisiones de lucha en las respectivas villas, impulsó la necesidad de conformar una nueva dirección integrada por los representantes de estos espacios, la Coordinadora de agrupaciones portuarias y un miembro de la dirección del SUPA, propuesta sistemáticamente rechazada tanto por el gremio como por las restantes agrupaciones. ${ }^{45}$

La huelga portuaria también fue para Política Obrera un debut en la lucha de calles. Tampoco poseía una presencia previa en el rubro portuario (más allá de algunos intentos fallidos de vinculación a través de "las ranchadas") y, a partir del estallido del conflicto, pugnó por forjar una inserción dentro de ciertas comisiones de resistencia en el marco de la organización

43. Solidaridad con los portuarios en huelga ( $20 \mathrm{de}$ octubre de 1966). Volante, PRT. AFP.

44. Boletín de informaciones (7 de noviembre de 1966). PRT, pp. 2-3; CC con invitados por regiones y zonas (17 de diciembre de 1966). CC del PRT. AFP.

45. Desgrabación del CC (17 de diciembre de 1966). Comité Central del PRT, pp. 1-4. AFP.

70 territorial. En términos discursivos, la actividad de PO se orientó en dos sentidos: participando como una corriente independiente de aquellas agrupaciones caracterizadas como burocráticas y, en simultáneo, augurando la necesidad de construcción de una nueva dirección. En relación con ello, al impulsarse Intervillas, este partido reconoció el papel de conducción desarrollado por el PRT atribuyéndole, al mismo tiempo, ciertas limitaciones. ${ }^{46} \mathrm{~A}$ partir de este análisis es que ofreció al PRT la posibilidad de forjar un frente único de intervención en la huelga portuaria. Estos debates fueron atravesados por divergencias en cuanto a la caracterización sobre el potencial de Intervillas. Mientras que PO sostenía la necesidad de que el SUPA incorporara a la coordinación de las villas como un actor reconocido en la dirección del conflicto; el PRT respondía que esa postura diluía a los flamantes organismos territoriales en una entidad más amplia que acabaría por subordinarlo. Finalmente, en un plenario conjunto de activistas de ambos partidos se concretó un frente con la premisa: "Fortalecer y reconocer a las comisiones de resistencia de las villas y la Intervillas como los únicos organismos de base en la actualidad del gremio portuario, exigiendo a la dirección de SUPA su participación directiva con pleno conocimiento de la marcha de las negociaciones y respetando su funcionamiento independiente". Este frente perduró hasta finales de diciembre, no solamente ante un claro descenso del propio conflicto sino también a partir de denuncias entre las dos organizaciones. ${ }^{47}$

46. La huelga portuaria y el frente único con el PRT (12 de diciembre de 1966). Política Obrera 9, pp. 17-23; La lucha portuaria (18 de enero de 1967). Política Obrera 10, pp. 7-15.

47. La huelga portuaria y el frente único con el PRT (12 de diciembre de 1966). Política Obrera 9, pp. 17-23; Boletín de informaciones (21 de noviembre de 1966). 
Como intento de continuidad, una vez finalizado el proceso huelguístico, $\mathrm{PO}$ impulsó una agrupación portuaria, Comité de Resistencia Portuaria 19 de Octubre, en la práctica sin posibilidad de desarrollo real alguno. $^{48}$

Menos significativo fue el papel sostenido por Vanguardia Comunista, organización maoísta fundada un año antes. Ante el estallido portuario, denunció que la confianza depositada por el SUPA hacia el golpe de Onganía se les volvió en contra y que los estibadores reaccionarían tanto contra las políticas del gobierno como contra los manejos burocráticos del sindicato. Resulta sintomático que en la propia documentación conocida de este partido (o bien, en balances posteriores) no se desprenda una participación de peso pero, no obstante en la documentación interna del PRT, se menciona que algunos militantes estudiantiles de VC esbozaron intentos de acercamiento a los portuarios. ${ }^{49}$

Por su parte, el PC tuvo una vinculación de cierto peso pero a través de entidades organizativas y esquemas de participación divergentes a las experiencias antes mencionadas. En primer lugar, a diferencia de las otras estructuras de izquierda, el PC poseía una agrupación portuaria con cierta presencia, La Lingada, que en las elecciones sindicales inmediatamente anteriores a la huelga sostuvo una línea de apoyo a la conducción de Tolosa (en el marco de una unidad de acción con

PRT; Boletín interno (27 de diciembre de 1966). PRT. AFP.

48. Portuarios: la lucha continúa (7 de febrero de 1967). Política Obrera 11, pp. 3 y 6.

49. Portuarios: reglamentación criminal (17 de octubre de 1966). No transar 62, p. 8. CeDInCI, Buenos Aires. el vandorismo que este partido sostuvo en el plano sindical). Eso lo llevó, en el derrotero del paro, a posicionarse dentro del juego de las disputas ínter-dirigenciales contraponiendo la actitud del tolosismo y de la conducción del SUPA al papel pasivo de la CGT. ${ }^{50}$ En ese marco, desarrolló dos modos de intervención. Centralmente, participó del conflicto a través de la Coordinadora de agrupaciones portuarias integrada por La Lingada junto a Justicia y Verdad y Cruzada Renovadora. Si bien, en su prédica, reivindicó al movimiento de base surgido desde las villas y otros organismos nacidos durante el conflicto, en la práctica este partido quedó subsumido a las lógicas desarrolladas por la dirección del SUPA y al desarrollo de un conflicto guiado por las estructuras tradicionales. Por ello, a través de volantes y de un boletín particular, Boletín del movimiento unitario La Lingada, esbozaron críticas a la CGT y, en menor medida, a la dirección del SUPA pero sin plantear una ruptura con su conducción.

En relación con lo dicho, La Lingada, tuvo cierta presencia territorial a través, por ejemplo, del impulso de las primeras ollas populares en las villas pero, una vez proliferado el movimiento de Comisiones de resistencia, el PC prácticamente ignoró este fenómeno al que no destinó parte activa de su militancia. De hecho, públicamente sugirió no participar de ellas para "no prestarse al juego de los políticos". En la misma línea, y como contraposición, participó de la Comisión Nacional de Ayuda al Estibador, a través de su militancia femenina participando de la recolección de vidrios, botellas y hierros para

50. La lucha portuaria (18 de enero de 1967). Política Obrera 10, pp. 7-15; El éxito del paro demuestra que la clase obrera enfrenta a la dictadura (20 de diciembre de1966). Nuestra Palabra 858, pp. 3-4. 
la obtención de fondos para los huelguistas. De igual modo, su intervención en Intercentros obstaculizó la participación estudiantil en este movimiento bajo el argumento de tratarse de clases sociales divergentes. ${ }^{51}$

Porúltimo, merece mencionarsela participación en el conflicto de una embrionaria izquierda peronista a través de Acción Revolucionaria Peronista (ARP), grupo fundado en 1963 bajo la dirección de John William Cooke. En cuanto a los posicionamientos con respecto a la conducción de la huelga, la ARP esgrimió un matiz de relieve en comparación al campo de las izquierdas. Caracterizó a la figura de Tolosa como un liderazgo burocrático pero representativo de las bases y del gremio portuario que sostuvo el conflicto. Por ello, dotar a la huelga de consignas antiburocráticas o contrarias a la conducción de Tolosa se revelaba un eje incorrecto siendo su crítica limitada a la pasividad mostrada por la CGT. En el mismo sentido, destacó como positivo el movimiento gestado desde las villas pero, aclarando, que en la pugna de grupos que allí se visualizaba era necesario el apoyo a la agrupación oficialista Justicia y Verdad. ${ }^{52}$

En la práctica, este agrupamiento impulsó la "Comisión de Solidaridad con la huelga

51. El éxito del paro demuestra que la clase obrera enfrenta a la dictadura (20 de diciembre de 1966). Nuestra Palabra 858, pp. 3-4; Portuarios: fracasan las recetas de la dictadura (29 de noviembre de 1966). Nuestra Palabra 855, p. 3; La huelga portuaria. Sus experiencias y enseñanzas, documento interno PRT, 1967.

52. (diciembre de 1966). Boletin interno Acción Revolucionaria Peronista (ARP) 1, p. 5. Archivo E1 Topo Blindado (ATB) http://eltopoblindado.com/; Los portuarios y la 'solidaridad' de la CGT (s/f). Lealtad. Boletin Gremial de Acción Revolucionaria Peronista 1, pp. 16-19. ATB. portuaria del Movimiento Peronista" con el objeto de promover la realización de mesas redondas y charlas en los barrios obreros; buscar el acercamiento con otros gremios y editar boletines, carteles y volantes en las villas. ${ }^{53} \mathrm{En}$ otro orden, se deduce de la documentación que la ARP tuvo cierta vinculación con la ocupación de la CGT. De hecho, su boletín interno reprodujo los dos comunicados de quienes tomaron la sede, apoyaron públicamente la acción y fue detenida su militante, Amanda Peralta, en las inmediaciones de la central por portación de armas. ${ }^{54} \mathrm{~A}$ la vez, fue justamente en el desarrollo de este conflicto cuando Norma Arrostito, proveniente del $\mathrm{PC}$, se vinculó al peronismo de Cooke (Saidón, 2005).

En otro orden, el peronismo tuvo también cierta intervención en el conflicto portuario desde la esfera estudiantil (por ejemplo, el Movimiento Universitario Popular de la Facultad de Derecho de la UBA desde donde participó Fernando Abal Medina) y a través del espacio territorial, centralmente a través de la figura de Carlos Mugica en la Villa 31 en donde, justamente, interactuó con el colectivo de Cooke. ${ }^{55}$ Sin embargo, no existió coordinación entre estos actores y los miembros de la publicación Cristianismo y Revolución, vinculada a la teología de la liberación, en la que el conflicto portuario se encontró prácticamente ignorado en sus páginas. Recién en noviembre de 1967, este medio realizó un análisis sindical y reprodujo un comunicado de la conducción del SUPA (firmado por Telmo Díaz y Rodolfo Basualdo) en el que refirió a la huelga portuaria de un año atrás criticando la actuación de la CGT

53. (diciembre de 1966). Boletín interno ARP 1, p. 5.

54. (2 de enero de 1967). Boletín interno ARP 2, p. 4.

55. (2 de enero de 1967). Boletín interno ARP 2, p. 4. 
en ese momento y planteando la necesidad de cambiar la metodología de conducción y elegir dirigentes que se sientan identificados con las necesidades de las bases. ${ }^{56}$

\section{Reflexiones finales}

En el marco del proceso de racionalización empresarial-estatal que llevó a la práctica la autodenominada Revolución Argentina tras el golpe de Estado de 1966, diversos rubros como el portuario, el ferroviario y el azucarero experimentaron los embates de las nuevas lógicas de ajuste pergeñadas por el "Onganiato". Si bien es factible aseverar que los resultados de aquellos intentos de freno a estas políticas fueron fallidos, la evaluación de tales experiencias merece una mayor profundidad. Así, en el presente artículo se indagó alrededor de la huelga portuaria, el primer ejemplo visible de oposición al régimen militar iniciado en junio de ese año. Si bien las reformas en las normativas y regimentaciones del trabajo impulsadas por el aparato gubernamental terminaron por imponerse, se destacan determinadas características y elementos en el transcurso del conflicto dignos de subrayar a los efectos de una indagación completa de este momento histórico.

La hipótesis que interesa a este trabajo retoma la afirmación que entiende que el período que dio inicio al "Onganiato" es factible de ser caracterizado como un retroceso pero no como un ciclo de derrotas para los trabajadores (Schneider, 2005). Subsidiaria a esta idea se sostiene otra premisa que atraviesa a

56. (diciembre de 1966). Boletín interno ARP 1, p. 8; La autocrítica sindical (noviembre de 1967). Cristianismo y Revolución 5, pp. 7-9. ATP. esta experiencia: el caso portuario permite vislumbrar la presencia embrionaria de diversos rasgos que marcarán la dinámica de la conflictividad social en la Argentina desde la concreción del Cordobazo en el marco de la radicalización de los años setenta y reflexionar entonces alrededor del año 1969 colocando un interrogante a la afirmación que identifica en ese momento una clara ruptura. En relación con ello, el conflicto portuario da cuenta de la presencia de disputas y tensiones dentro del campo de las dirigencias y organismos sindicales, un fenómeno extendido en este ciclo de protestas de los años sesenta y setenta que, seguramente, encontraría su ejemplo de mayor fortaleza con la posterior aparición de la CGT de los Argentinos (Bozza, 2009; Dawyd, 2014; James, 1990 y Schneider, 2005).

En otro orden, la vinculación entre la esfera sindical y aquella territorial (en este caso, mediante la gestación de un movimiento de peso en los núcleos de residencia de los propios estibadores que pretendió superar a los organismos tradicionales del movimiento obrero) fue un claro fenómeno que anticiparía ciertas experiencias surgidas con posterioridad al mayo cordobés como, por ejemplo, las instancias de coordinación de familiares o mujeres de trabajadores en conflicto que se visualizaron en el espacio territorial en las luchas de Villa Constitución (Prospitti y Videla, 2012, Rodríguez y Videla, 1999, Santella y Andújar, 2007). Del mismo modo, la solidaridad e intentos de articulación entre los trabajadores portuarios y otros rubros pertinentes al mundo del trabajo como así también las muestras de adhesión y participación del movimiento estudiantil, si bien embrionario, resulta un aspecto que presagia un repertorio mayormente visible desde finales de los años sesenta (Brenann y 
Gordillo, 2008, Gordillo, 2003, Raimundo, 2012).

Por último, la inserción y actuación de diversas tendencias del campo de las izquierdas, tanto en sus variantes marxistas como peronistas, dan cuenta de ciertas lógicas que son factibles de ser identificadas como componentes inherentes a una conflictividad visualizada con claridad luego de los sucesos de mayo de 1969 en el derrotero que siguió al Cordobazo (Gillespie, 1987; Löbbe, 2009; Pozzi y Schneider, 2000; Werner y Aguirre, 2007). No obstante, en el desarrollo de este conflicto se sostuvo que esta presencia militante es un aspecto inherente a la comprensión en torno a su larga durabilidad.

En definitiva, en un contexto de ofensiva y racionalización por parte de la dictadura militar en consonancia con el empresariado contra las condiciones de los trabajadores, resulta menester abordar estos ejemplos de resistencia temprana y pensarlos a la luz del proceso de radicalización político-ideológica que se experimentaría con claridad a finales de los años sesenta y principios de los setenta dando cuenta de rupturas o virajes menos tajantes y de la presencia de diversos elementos de notoria continuidad entre ambos momentos históricos.

$$
\propto \tilde{e} \propto
$$

Recibido: 11-06-2018

Aceptado: 31-10-2018

Publicado: 04-06-2019 


\section{Referencia Bibliográficas}

Agostini, C. y Saavedra, E. (2003). Chile: congestión portuaria y racionamiento eficiente en la transferencia de carga, CEPAL, (111).

Anzorena, O. (1988). Tiempo de violencia y utopia (1966-1976). Buenos Aires: Contrapunto.

Berrotarán, P. y Villarroel, J.(1994). Tiempos de derrota: los estibadores de Buenos Aires (1955-1966). En P. Berrotarán y P. Pozzi (Comps.), Estudios inconformistas sobre la clase obrera argentina (pp. 71-87). Letra Buena, Buenos Aires, 1994.

Bozza, J. A. (2009). La voluntad organizada. La CGT de los Argentinos, una experiencia de radicalización sindical, Anuario del Instituto de Historia Argentina, (9), 179-208.

Brenann, J. y G., M. (2008). Córdoba rebelde. El Cordobazo, el clasismo y la movilización social. Buenos Aires: Editorial De la Campana.

Dawyd, D. (2014). El sindicalismo peronista durante el Onganiato. De la CGT de los Argentinos a la reorganización sindical (1968-1970), Sociohistórica, (33). Recuperado de https://www.sociohistorica.fahce. unlp.edu.ar/article/view/SH2014n33a04

Doerr, O. (2011). Politicas portuarias, Serie Recursos naturales e infraestructura-CEPAL. Documento del CEPAL. Buenos Aires: CEPAL.

Gillespie, R. (1987). Montoneros. Soldados de Perón. Buenos Aires: Grijalbo.

González, E. (Coord.). (1999). El trotskismo obrero e internacionalista en la Argentina. Tomo 3: Palabra Obrera, el PRT y la Revolución Cubana. Volumen 2 (1963-1969). Buenos Aires: Antídoto.

Gordillo, M. (2003). Protesta, rebelión y movilización: de la resistencia a la lucha armada, 1955-1973. En D. James (Dir.), Violencia, proscripción y autoritarismo (1955-1976) (pp. 329-380). Buenos Aires: Editorial Sudamericana.

James, D. (1990). Resistencia e integración. El peronismo y la clase trabajadora argentina, 1946-1976. Buenos Aires: Sudamericana.

Löbbe, H. (2009). La guerrilla fabril. Clase obrera e izquierda en la Coordinadora de Zona Norte del Gran Buenos Aires (1975-1976). Buenos Aires: RyR.

Mangiantini, M. (2018). Itinerarios militantes. Del Partido Revolucionario de los Trabajadores al Partido Socialista de los Trabajadores (1965-1976).Buenos Aires: Imago Mundi.

Nieto, A. (2011). Activación obrera y democracia. Experiencias micropolíticas de un grupo subalterno: Las obreras/os del pescado, Mar del Plata (1942-1966). A Contracorriente, 9(1), 175-202.

O’Donnell, G. (1982). El estado burocrático autoritario. Triunfos, derrotas y crisis. Buenos Aires: Editorial de Belgrano. 
Peralta Ramos, M. (2007). La economía politica argentina: poder y clases sociales (1930-2006). Buenos Aires: Fondo de Cultura Económica.

Pozzi, P. y Schneider, A. (2000). Los setentistas. Izquierda y clase obrera: 1969-1976. Buenos Aires: Eudeba.

Prospitti, A. y Videla, O. (2012). La conformación de una comunidad obrera en Villa Constitución”, Cuadernos del Ciesal, 9(11), 29-58, 2012.

Raimundo, M. (2012). Grandes huelgas platenses durante la Revolución Argentina en perspectiva comparada. En C. Castillo y M. Raimundo (Comps.), El 69 platense. Luchas obreras, conflictos estudiantiles y militancia de izquierda en La Plata, Berisso y Ensenada durante la Revolución Argentina (pp. 235-267). Buenos Aires: Estudios Sociológicos Editora.

Rodríguez, E. J.y Videla O. (Comps.). (1999). El Villazo. La experiencia de una ciudad y su movimiento obrero. Villa Constitución: Revista Historia Regional Libros, 1999.

Saidón, G. (2005). La montonera. Biografía de Norma Arrostito. Buenos Aires: Sudamericana.

Santella, A. y Andújar, A. (2007). El Perón de la fábrica éramos nosotros: las luchas de Villa Constitución, 19701976. Buenos Aires: Desde el subte.

Schneider, A. (2005). Los compañeros. Trabajadores, izquierda y peronismo (1955-1973). Buenos Aires: Imago Mundi.

Sepúlveda Ortíz, J. (1987). Política portuaria", Revista de Marina, (776). Recuperado de https://revistamarina.cl/revistas/1987/1/sepulveda.pdf

Snitcofsky, V. (2011). Villas de Buenos Aires y conflictos portuarios bajo el gobierno de Onganía: aportes para un análisis de la articulación entre sindicalismo de base y organización territorial. En V. Basualdo (Coord.), La clase trabajadora argentina en el siglo XX: experiencias de lucha y organización (pp. 51-80). Buenos Aires: Atuel.

Tolosa, E. (1969). ¿El problema portuario argentino resuelto? ;Qué ganas de macanear!. Buenos Aires, s/e.

Werner, R. y Aguirre, F. (2007). Insurgencia obrera en la Argentina, 1969-1976. Clasismo, coordinadoras interfabriles y estrategias de la izquierda. Buenos Aires: Ediciones IPS.

Zapata, A. B. (2017). Portuarios en lucha: de la huelga, a la demanda por un "Puerto- Fábrica" Bahía Blanca-Ingeniero White (1966-1971). Archivos de Historia del Movimiento Obrero y la Izquierda, 6(11), 163-182. 